\title{
An evaluation of the medical internship programme at King Edward VIII hospital, South Africa in 2016
}

\author{
Andrew Ross*, SS (Cyril) Naidoo and Siyabonga Dlamini \\ Department of Family Medicine, University of KwaZulu-Natal, Durban, South Africa \\ *Corresponding author, email: rossa@ukzn.ac.za
}

Background: In 2005, the Health Professions Council of South Africa (HPCSA) extended the duration of the internship programme to ensure that all young medical graduates are adequately prepared to work at a district hospital during their year of community service. King Edward VIII hospital (KEH) is an HPCSA accredited training hospital, which has been training interns for many years. The aim of this study was to assess intern perceptions of their training at the hospital.

Methods: This cross-sectional, descriptive study was conducted at KEH in November 2016. A questionnaire was used to collect data, which were analysed descriptively.

Results: Only $53 \%$ of interns completed the questionnaire. Although teaching and supervision were provided in all domains, perceptions of the quality ranged from excellent to poor. The majority of interns worked the 64-80 hours per month commuted overtime as required by the HPCSA. However, less than $10 \%$ expressed positive views regarding the condition of the facilities and infrastructure.

Discussion and conclusions: The findings of this study were generally positive with regard to teaching, supervision and hours worked, mostly in accordance with the requirements of the HPCSA. However, a response rate of $53 \%$ as well as the single location of the study may limit generalisability and a larger study involving interns across the country is recommended.

Keywords hours worked, internship, South Africa, supervision, training

\section{Introduction and background}

Current medical training in South Africa (SA) involves six years of instruction at university, followed by a two-year internship at a Health Professions Council of South Africa (HPCSA) accredited training facility. This is followed by one year of community service before medical healthcare professionals (HCPs) can be registered as independent medical practitioners. ${ }^{1,2}$

In 2005, due to concerns about the high rate of maternal mortality and poor anaesthetic and clinical competencies among medically qualified HCPs during their community service year, the HPCSA modified the duration of the internship programme and extended it from a one-year to a two-year programme. ${ }^{2,3}$ The extended programme makes it compulsory for all interns to rotate through all of the major clinical domains (medicine, surgery, obstetrics, paediatrics, anaesthetics, orthopaedics, family medicine and psychiatry) in an attempt to ensure that young graduates are competent and adequately prepared to work at a district hospital during their year of community service. ${ }^{2-4}$

The internship programme in SA is based on an apprenticeship model $^{5}$ in which interns 'learn by doing' under supervision. Guidelines are provided by the internship subcommittee of the HPCSA to the interns and the training institutions concerning the level of supervision that must be provided; teaching (formal and informal/bedside) responsibilities of the training institution; need to provide guidelines for managing common conditions, number of hours that interns can work each week, provision of suitable on-call facilities, and other issues that relate directly or indirectly to training interns. ${ }^{4}$

In addition to the guidelines provided, and to ensure maintenance of high training standards at hospitals where internship training occurs, members of the HPCSA intern subcommittee visit each training institution on a bi-annual basis. These visits provide the opportunity to reinforce the purpose and methods of the internship training, the HPCSA expectations and logbook requirements. At these visits, senior members of the hospital staff and interns are interviewed to assess the amount of teaching, training and supervision provided, hours that interns are working, and working conditions for the interns (e.g. resting facilities, on-call rooms, ease in obtaining blood results, intern accommodation etc.). The logbooks are also reviewed to ensure that they are being appropriately completed and signed off at the end of each rotation. Written feedback from these visits is given to the hospital and to the intern subcommittee and recommendations are made to address any issues pertaining to training that are identified at the visit.

Concerns have, however, been raised regarding the level of supervision provided to interns, and the consistency of teaching and training at some of the hospitals where interns are working. ${ }^{3}$ A research study published in the South African Medical Journal in $2012^{1}$ reported that supervision, teaching and training, as well as hours that interns were expected to work, were not in keeping with the guidelines provided by the subcommittee.

A 2015 inspection of the internship programme at King Edward VIII hospital (KEH) in KwaZulu-Natal by members of the internship subcommittee of the HPCSA identified gaps in the training and supervision provided to interns in a number of departments. In order to address the deficiencies referred to in the report, heads of clinical units requested a more detailed evaluation of the internship programme at the hospital to determine whether the teaching, training, supervision and hours worked were consistent with the guidelines provided by the internship subcommittee of the HPCSA. ${ }^{4}$ 
This study was therefore undertaken to assess the two-year internship programme at KEH with an emphasis on: (a) the teaching and supervision provided to interns, (b) the hours interns worked, (c) whether the facilities and infrastructure were in line with the guidelines provided by the HPCSA, and (d) the overall perception of interns regarding their training and career plans

\section{Research methods}

King Edward VIII hospital is a 922-bedded hospital with \pm 360000 out patients and is the second largest hospital in the southern hemisphere, providing regional and tertiary services to the whole of KwaZulu-Natal and parts of the Eastern Cape province. ${ }^{6}$ The hospital is also a teaching hospital for the University of KwaZulu-Natal's Nelson R Mandela School of Medicine and has a nursing college attached to it. Forty interns are allocated to $\mathrm{KEH}$ each year, giving a total of 80 interns training at any particular time of the year ( 40 first years and 40 second years). Every intern is expected to remain at KEH for the two-year duration of their internship, and to rotate through all of the major clinical domains (four months of medicine, obstetrics and gynaecology, paediatrics and surgery, three months of family medicine, one month of psychiatry and two months of anaesthetics and orthopaedics).

According to the 2016 HPCSA guidelines for internship training, each intern is expected to work a 40-hour week, with no more than 20 hours of commuted overtime per week, and continuous service should not exceed 30 hours. Supervision must be provided by a registered medical practitioner with at least three years (post-internship training) of clinical experience in that specific domain of training. Although access to such a supervisor should be available 24 hours a day, the guidelines make provision for interns to be supported at the 'coal face' by relatively junior doctors (doing community service or post-community service), with the responsibility of supervision and patient care resting with the more senior person, whether a medical officer or consultant. ${ }^{4}$

This was a descriptive cross-sectional study. The study population was all interns working at KEH in November 2016 and there were no exclusion criteria. Data were collected by means of a questionnaire developed by members of the HPCSA internship subcommittee based on the logbook requirements and the HPCSA guidelines on internship. ${ }^{4}$ Additional input during the development of the questionnaire was provided by members of the Junior Doctors Association of South Africa (JUDASA) and the questionnaire was piloted among 10 interns based at Baragwaneth hospital to ensure that the questions were clear and unambiguous. The following variables were collected in the questionnaire: (a) demographic (age, sex, university where qualified, current hospital where working), (b) teaching and supervision, (c) hours worked, (d) facilities and infrastructure (rest rooms, on-call facilities, ease in obtaining results), (e) perception of the internship, and ( $f$ ) long-term plans. Participants were asked to complete the questionnaire based on their understanding of the intern guidelines and definitions provided in the guidelines, and to provide feedback only on the domains through which they had rotated. A Likert scale from 1 to 7 , where 1 was not at all and 7 was greatly, was used to assess curator availability, suitability of facilities at the hospital for internship training as well as perceptions of internship training. A three-point Likert scale was used to assess quality of the supervision and teaching, with interns choosing either excellent, good or poor based on their own subjective experiences. The data collected was entered into a Microsoft Excel $^{\oplus}$ (Microsoft Corp, Redmond, WA, USA) spreadsheet and analysed using IBM SPSS $^{\oplus}$ statistical software program version 24 (IBM Corp, Armonk, NY, USA).

\section{Results}

In total, $41 / 78$ (53\%) interns completed the questionnaire, of whom 23 were women and 17 were men. The average age was 26.03 years (range 24-36 years), and 20 interns were in their first year and 21 were in their second year of internship. Ten of the interns had graduated from Pretoria University, eight from the University of Witwatersrand, seven from Stellenbosch University, six from the University of KwaZulu-Natal, three from the University of Cape Town, Free State University and foreign universities and one from Sefako Makhato University. Of the three interns who were foreign trained one graduated from each of India, South Korea and Romania. KEH was first choice for 32/41 (78\%), second choice for $4 / 41$ (10\%), third choice for one, fourth choice for one and $>$ fourth choice for two interns. The majority of interns (38/40; 95\%) felt that medical school had adequately prepared them for their internship.

Table 1 presents the perceived quality of supervision in all eight domains, both during normal hours and after hours. The quality of the supervision varied across the domains, with anaesthetics perceived to be providing excellent supervision by more than $90 \%$ of the interns that responded to this question.

Additionally, when asked specifically about supervision by a registered medical practitioner with at least three years' postinternship clinical experience, 10/32 (31.3\%) interns reported that in family medicine they were often supervised by

Table 1: Supervision of interns during normal hours and after hours at KEH

\begin{tabular}{|c|c|c|c|c|c|c|}
\hline \multirow[b]{2}{*}{ Domain } & \multicolumn{3}{|c|}{ Supervision provided during normal hours (\%)* } & \multicolumn{3}{|c|}{ Supervision provided after hours (\%)* } \\
\hline & Excellent & Good & Poor & Excellent & Good & Poor \\
\hline Anaesthetics, $n=26^{*}$ & $26(100)$ & $0(0)$ & $0(0)$ & $23(92.0)$ & $2(8.0)$ & $0(0)$ \\
\hline Family medicine, $n=32$ & $12(37.5)$ & $19(59.4)$ & $1(3.1)$ & $4(12.5)$ & $26(81.25)$ & $2(6.25)$ \\
\hline Medicine, $n=27^{*}$ & $11(42.3)$ & $15(57.7)$ & $0(0)$ & $7(27.0)$ & $19(73.0)$ & $0(0)$ \\
\hline O\&G, $n=34$ & $6(17.6)$ & $25(73.5)$ & $3(8.8)$ & $4(11.8)$ & $27(79.4)$ & $3(8.8)$ \\
\hline Orthopaedics, $n=25$ & $4(16.0)$ & $11(44.0)$ & $10(40.0)$ & $2(8.0)$ & $15(60.0)$ & $8(32.0)$ \\
\hline Paediatrics, $n=33^{*}$ & $25(75.8)$ & $7(21.2)$ & $0(0)$ & $21(67.7)$ & $10(32.3)$ & $0(0)$ \\
\hline Psychiatry, $n=28^{*}$ & $7(25.0)$ & $18(64.3)$ & $3(10.7)$ & $3(15.0)$ & $15(75.0)$ & $2(10.0)$ \\
\hline Surgery, $n=28$ & $7(25.0)$ & $17(60.7)$ & $4(14.3)$ & $5(17.85)$ & $18(64.3)$ & $5(17.85)$ \\
\hline
\end{tabular}

*Some data are incomplete due to non-response to parts of the questionnaire. 
someone with $<3$ years' experience while in orthopaedics, paediatrics and surgery they were occasionally supervised by a medical officer with $<3$ years' experience $(8 / 25,6 / 33,4 / 28$ respectively). Just under half of the interns $(17 / 41 ; 41 \%)$ indicated that they had done procedures for the first time without supervision, which included insertion of a central venous pressure (CVP) line (7 interns), intercostal drain insertion (11 interns), debridement of a wound ( 1 intern) and incision and drainage of an abscess (I\&D) (1 intern).

Formal and informal teaching were provided in all domains, with anaesthetics, family medicine, obstetrics and gynaecology, and paediatrics providing formal teaching twice a week (17/26, 18/ $32,13 / 34$ and 19/33 respectively), while medicine, psychiatry and surgery provided formal teaching on a weekly basis (11/ $27,17 / 28,13 / 28$ respectively). The perceived quality of formal and informal teaching is reported in Table 2.

A block orientation at the start of each rotation was organised in all domains. However, regular documented meetings with interns were reported by less than $50 \%$ of interns in all domains (anaesthetics 21/26, family medicine 14/32, medicine $7 / 27$, O\&G $5 / 34$, orthopaedics $7 / 25$, paediatrics $15 / 33$, psychiatry $4 / 28$ and surgery $3 / 28)$.

Interns were asked to indicate how often they were expected to work beyond their normal working hours and how much overtime they were expected to perform; the details are provided in Table 3.

Interns in anaesthetics and psychiatry rarely worked outside of their contracted 40 hours/week while those in the other domains worked beyond their contracted 40 hours/week at least twice a month. Most interns reported working 64-80 hours' commuted overtime a month, as required by the HPCSA. However, a number of interns in family medicine (3/ $32)$, medicine (2/27), O\&G (7/34), orthopaedics (3/25), paediatrics $(2 / 33)$ and surgery (4/28) reported working more than 100 hours/month of commuted overtime. Interns felt that the following factors contributed to long hours: shortage of staff (23/41), too many patients (24/41), little help from nursing staff (16/41) and little help from medical officers (21/41).

Only $2 / 41$ (4.9\%) of the interns felt that the facilities and infrastructure at the hospital were completely suitable for internship training, $5 / 41(12 \%)$ felt that the facilities were completely unsuitable for internship training and 33/41 (80.1\%) were ambivalent about the facilities (mean 4.98, median 5, SD 1.4, range 0-7). Only $3 / 41(7.3 \%)$ felt that their internship was well organised, $1 / 41(2.4 \%)$ felt that it was poorly organised and $37 / 41(90.2 \%)$ felt that the organisation of their internship was adequate (mean 4.93, median 5, SD 1.03, range 1-7). Only two interns considered the site was conducive to learning, 37 (90.2\%) were ambivalent and $1 / 41$ (2.4\%) felt that the site was not conducive to learning (mean 4.76, median 5, SD 1.04, range 1-7). Regarding

Table 2: Interns' perception of the quality of formal and informal teaching received at KEH

\begin{tabular}{|c|c|c|c|c|c|c|}
\hline \multirow[b]{2}{*}{ Domain } & \multicolumn{3}{|c|}{ Informal teaching (\%) } & \multicolumn{3}{|c|}{ Formal teaching $(\%)^{*}$} \\
\hline & Excellent & Good & Poor & Excellent & Good & Poor \\
\hline Anaesthetics, $n=26$ & $21(80.8)$ & $5(19.0)$ & $0(0)$ & $24(92.3)$ & $2(7.7)$ & $0(0)$ \\
\hline Family medicine, $n=32$ & $6(18.8)$ & $21(65.6)$ & $5(15.6)$ & $7(21.8)$ & $24(75.0)$ & $1(3.1)$ \\
\hline Medicine, $n=27^{*}$ & $5(18.5)$ & $15(55.6)$ & $7(25.9)$ & $3(12.0)$ & $17(68.0)$ & $5(20.0)$ \\
\hline $\mathrm{O} \& \mathrm{G}, n=34^{*}$ & $1(3.0)$ & $15(45.5)$ & $17(51.5)$ & $4(11.8)$ & $17(50.0)$ & $13(38.2)$ \\
\hline Orthopaedics, $n=25$ & $1(4.0)$ & $16(64.0)$ & $8(32.0)$ & $1(4.0)$ & $16(64.0)$ & $8(32.0)$ \\
\hline Paediatrics, $n=33$ & $11(34.4)$ & $20(62.5)$ & $1(3.1)$ & $23(71.9)$ & $9(28.1)$ & $0(0)$ \\
\hline Psychiatry, $n=28$ & $1(3.6)$ & $17(60.7)$ & $10(35.7)$ & 1 (3.6) & $16(57.1)$ & $11(39.2)$ \\
\hline Surgery, $n=28^{*}$ & $2(7.1)$ & $16(57.1)$ & $10(35.7)$ & $3(11.1)$ & $10(37.0)$ & $14(51.9)$ \\
\hline
\end{tabular}

*Some data are incomplete due to non-response to parts of the questionnaire.

Table 3: Frequency of interns working outside contracted working hours (e.g. outside 8 am-4 pm) as well as amount of commuted overtime worked in each domain

\begin{tabular}{|c|c|c|c|c|c|c|c|c|c|}
\hline \multirow[b]{2}{*}{ Domain } & \multirow[b]{2}{*}{$\begin{array}{l}\text { Total } \\
(N)\end{array}$} & \multicolumn{4}{|c|}{$\begin{array}{c}\text { Frequency of interns working beyond normal } \\
\text { working hours* }\end{array}$} & \multicolumn{4}{|c|}{ Commuted overtime hours worked by interns* } \\
\hline & & $\begin{array}{l}\text { Every } \\
\text { day }(\%)\end{array}$ & $\begin{array}{c}1-2 \text { x } \\
\text { /week } \\
(\%)\end{array}$ & $\begin{array}{c}1-2 \times \\
\text { /month } \\
(\%)\end{array}$ & $\begin{array}{l}\text { Never } \\
(\%)\end{array}$ & $\begin{array}{c}<64 \text { hours' } \\
\text { overtime } \\
(\%)\end{array}$ & $\begin{array}{c}64-80 \\
\text { hours' } \\
\text { overtime } \\
(\%)\end{array}$ & $\begin{array}{c}81-100 \\
\text { hours' } \\
\text { overtime } \\
(\%)\end{array}$ & $\begin{array}{c}>100 \\
\text { hours' } \\
\text { overtime } \\
(\%)\end{array}$ \\
\hline Anaesthetics* & 26 & $0(0)$ & $2(8.3)$ & $4(16.7)$ & $18(75.0)$ & $7(30.4)$ & $14(60.9)$ & $2(8.7)$ & $0(0)$ \\
\hline $\begin{array}{l}\text { Family } \\
\text { medicine* }^{*}\end{array}$ & 32 & $0(0)$ & $8(25.0)$ & $9(28.1)$ & $14(43.8)$ & $2(6.5)$ & $20(64.5)$ & $6(19.4)$ & $3(9.7)$ \\
\hline Medicine ${ }^{*}$ & 27 & $1(3.8)$ & 9 (34.6) & 9 (34.6) & $7(27.0)$ & $1(4.0)$ & $16(64.0)$ & $6(24.0)$ & $2(8.0)$ \\
\hline$O \& G^{*}$ & 34 & $4(11.8)$ & $4(11.8)$ & $8(23.5)$ & $18(52.9)$ & $1(3.3)$ & $13(43.3)$ & $9(30.0)$ & $7(23.3)$ \\
\hline Orthopaedics* & 25 & $0(0)$ & $8(33.3)$ & $8(33.3)$ & $8(33.3)$ & $0(0)$ & $10(45.5)$ & $9(40.9)$ & $3(13.6)$ \\
\hline Paediatrics* & 33 & $0(0)$ & $3(10.0)$ & $7(23.3)$ & $20(66.7)$ & $1(3.4)$ & $25(86.2)$ & $1(3.4)$ & $2(6.9)$ \\
\hline Psychiatry* & 28 & $0(0)$ & $0(0)$ & $2(7.4)$ & 25 (92.6) & $7(35.0)$ & $13(65.0)$ & $0(0)$ & $0(0)$ \\
\hline Surgery* & 28 & $3(11.5)$ & 9 (34.6) & 9 (34.6) & $5(19.2)$ & $0(0)$ & $12(48.0)$ & $9(36.0)$ & $4(16.0)$ \\
\hline
\end{tabular}

*Some data are incomplete due to non-response to parts of the questionnaire. 
their level of satisfaction with their internship experience, 4/41 $(10 \%)$ were very satisfied with their internship experience, $3 / 41$ (7.3\%) were totally dissatisfied with their internship experience, and 34/41 (82.9\%) were satisfied with their internship experience (mean 4.98, median 5, SD 1.17, range 1-7). Just two interns (5\%) felt that their internship had adequately prepared them for community service, $3 / 41$ (7.3\%) felt that they were completely unprepared for community service, whereas $34 / 41$ $(82.9 \%)$ felt somewhat prepared for community service (mean 4.59 , median 5, SD 1.43, range $0-7$ ).

Regarding future plans, 2 (5\%) interns planned to emigrate, 7 (17\%) to work overseas to gain experience, 12 (29\%) to work in the public sector for the purpose of specialisation, $3(7 \%)$ to work in the public sector but not necessarily to specialise, 14 (34\%) were undecided and 4 (7\%) to work in the private sector in South Africa. Many cited the uncertainty of posts and their future in the public health sector as a reason for their uncertainty concerning their future plans.

\section{Discussion}

Just over $50 \%(41 / 80)$ of interns working at the hospital completed the questionnaire, which is a significant limitation of the study. Only those who had completed a particular block filled in the assessment of that block, which further reduced the number of responses for each section of the questionnaire.

Interns working at the hospital come from all of the medical schools in South Africa with the majority from the University of Pretoria in Gauteng Province. There has previously been an attempt to ensure an equitable distribution of interns from all of the universities. However, since 2016 there has been a computer allocation process for intern and community service placement, which might influence the spread of interns from each university. Regarding gender, 56\% (23/41) of the interns were women, which is similar to the percentage of women graduates from South African universities. There has been some concern about the increasing number of women in the profession impacting on the ability to run the health services, particularly if those with young families opt not to participate in overtime call rosters. ${ }^{7}$ In keeping with other studies ${ }^{2,3}$ the majority of those who responded felt that medical school had adequately prepared them for internship. This is however, a self-reflection where confidence may exceed competence and may not reflect the expectations of the training staff at the hospital.

In general, supervision was considered good both during the normal hours (8.00-16.00) and after hours, with only supervision in orthopaedics considered poor by $40 \%(10 / 25)$ of interns during normal hours. Anaesthetics and paediatrics provided excellent supervision both during normal working hours and after hours. Excellent supervision and teaching in anaesthetics is a common finding in the HPCSA inspections as the ratio of patients to doctors is always $1: 1$. Supervision after hours was generally good with only $2 / 32(6 \%)$ in family medicine, 3/34 (9\%) in obstetrics, 8/25 (32\%) in orthopaedics, 2/28 $(7 \%)$ in psychiatry and $5 / 28(18 \%)$ in surgery describing the after-hours supervision as poor. Although some supervision was provided by medical officers with less than three years' post-graduation experience (particularly in family medicine), this is allowed by the HPCSA guidelines with the stipulation that only the domain trainer (supervisor) needs to have a minimum of three years' post-graduation experience in that domain. $^{4}$
Despite the good supervision reported, a number of interns indicated that they had been asked to do procedures for the first time without supervision, specifically the insertion of intercostal drains and the insertion of central lines. These are the same procedures reported from a national study done in 2013 among 90 interns, but less than the $30 \%$ of interns who reported having to do a procedure for the first time without supervision in that study. ${ }^{3}$ As KEH is a tertiary training hospital with registrars in all clinical domains, it was surprising to find interns doing procedures for the first time without supervision.

As internship is based on an apprenticeship model, appropriate informal (bedside) and formal teaching is important to enable interns to apply knowledge in a particular context. Formal teaching occurred in all domains on at least a weekly basis with formal teaching occurring more than weekly in anaesthetics, family medicine and paediatrics. In general, teaching (both formal and informal) was good to excellent, which was better than the findings of Bola, ${ }^{3}$ with only the informal and formal teaching in obstetrics (17/34), psychiatry (10/28) and surgery (10/28) described as poor. Teaching and supervision are considered by the HPCSA to be at the core of intern training and an emphasis is placed on ensuring that these components are adequately provided when the inspection visits are conducted. ${ }^{4}$ In addition to the inspections by the HPCSA each department is expected to have monthly documented meetings with the interns so that issues relating to teaching and supervision can be discussed. As regular departmental meetings with the interns were reported to be infrequent in some departments, the opportunity to address any deficiencies 'in house' may have been missed. Recognising the importance of teaching and supervision of internship, it is hoped that an electronic logbook will be introduced by the internship committee of the HPCSA in 2019. Built into the logbook will be regular evaluations of the supervision and training being provided to each intern at each training institution. This will allow the HPCSA internship committee to access real-time data on the quality of teaching and training at every training institution in the country, and to timeously plan interventions at hospitals supervising interns as deficiencies are identified.

In contrast to other studies ${ }^{1,3}$ most interns reported working the prescribed 40 hours per week and $60-80$ hours' commuted overtime per month. The internship is part of professional training and from time to time interns would be expected to remain on duty to cover an emergency or some unexpected event; however, this should be the exception and not a regular event. Reasons for working longer than the prescribed hours are similar to those given in previous studies and included shortage of staff, too many patients, and little help from the nursing staff and from other medical officers. ${ }^{1,3}$ Of concern is that $30 \%$ of interns reported working $80-100$ hours' commuted overtime (rather than the 60-80 hours prescribed) in obstetrics, orthopaedics and surgery and $20 \%$ reported working more than 80 hours in family medicine. This is, however, less than the excessive overtime hours (200+ hours) reported in $2012^{1}$ and in $2015^{3}$ but still a cause for concern, as it exceeds the recommendation of the HPCSA. However, the results from this study suggest that the experiences of interns reported at Baragwaneth hospital ${ }^{1}$ are not necessarily reflective of the experiences of interns across the country and that the guidelines provided by the HPCSA are used to ensure that interns work the prescribed number of hours.

The hours worked by interns have recently come under the spotlight, with studies ${ }^{8}$ suggesting that working in excess of 24 
continuous hours can result in impaired decisions and an increase in adverse events impacting on patients and doctors. Following the death of a doctor in an accident when driving home after a 30-hour shift, ${ }^{9}$ the internship committee of the HPCSA recommended in 2017 that the maximum continuous shift that an intern could work be reduced from 30 hours to 26 hours. This, however, is more than the 20 hours' continuous shift recommended by some European countries. ${ }^{8}$ Reducing the continuous hours worked by interns, while considered to be a progressive step, will have an impact on the number of staff needed as well as on continuity of care as those who have worked through the night will not be available to hand over patients at the post-intake ward round.

The interns were ambivalent about the suitability of the training facilities, the organisation of the internship and whether or not the hospital was conducive to internship training. That the facilities were perceived as less than ideal was not surprising as $\mathrm{KEH}$ was built in the 1940s and the hospital infrastructure is crumbling. A new hospital has been in the pipeline for more than 20 years but with the funding crisis in the KwaZulu-Natal Department of Health this is unlikely to materialise in the near future. Most interns were ambivalent as to whether or not they were adequately prepared for community service (CS). Only 2/41 felt that their internship at KEH adequately prepared them for the challenges of working independently in a district hospital during CS. This is lower than the $81 \%(73 / 90)$ of doctors who completed their internship in 2013 who participated in a national survey, ${ }^{3}$ and the $78 \%$ of community service doctors working in 22 district hospitals in KwaZulu-Natal surveyed in $2013{ }^{2}$ who felt that their internship adequately prepared them for CS. However, in reality it is difficult for interns to assess their preparedness for CS without any experience of it. It was interesting to note the career plans for these interns, with two interns planning to emigrate and the current staffing crisis having an impact on interns' long-term plans.

\section{Limitations}

A response rate of just over $50 \%$, as well as the single study location, may limit the generalisability of the findings. In addition, not providing clear definitions on terms may be a limiting factor as terms such as 'adequate supervision' and 'regular meeting' could have a quite different meaning to different interns. Interns were, however, asked to base their responses on the guidelines provided by the HPCSA ${ }^{4}$ where these terms are clearly defined.

\section{Conclusions and recommendations}

In general, the teaching, supervision and hours worked at this tertiary teaching hospital were adequate and were in accordance with the requirements of the HPCSA. However, there is room for improvement in a number of domains. It is recommended that a larger national study be conducted to assist in understanding the perceptions of interns and the impact of the current programme on their training and preparation for future practice.

\section{Authors' contribution}

AR wrote the protocol, collected the data and wrote the first draft and final manuscript. SSN contributed to the development of the data collection tool, and write-up of the final manuscript. SD analysed the data and contributed to the final manuscript.

Disclosure statement - No conflict of interest was reported by the authors.

Ethical clearance statement - Ethics approval for this study was given by the Biomedical Research Ethics committee (BREC) of the University of KwaZulu-Natal (BREC reference number: $B E 370 / 16)$. Permission to do this study was given by the CEO of KEH and the provincial Department of Health. Participants signed a consent form after reading an information sheet.

Funding - This research was self-funded.

\section{References}

1. Erasmus N. Slaves of the state - medical internship and community service in South Africa. S Afr Med J. 2012;102(8):655-8.

2. Nkabinde TC, Ross A, Reid S, Nkwanyana NM. Internship training adequately prepares South African medical graduates for community service - with exceptions. S Afr Med J. 2013;103(12):930-4.

3. Bola S, Trollip E, Parkinson F. The state of South African internships: a national survey against HPCSA guidelines. S Afr Med J. 2015;105 (7):535-9.

4. Guidelines for internship training 2016. In: Africa HPCSA, editor. Pretoria: Health Professions Council of South Africa; 2015.

5. Van Niekerk J. Internship and community service require revision. S Afr Med J. 2012;102(8):638.

6. KZN Department of Health. King Edward VIII hospital: KwaZulu Natal Department of Health; Available from: http://www.kznhealth.gov.za/ kingedwardhospital.htm

7. Meirion Thomas J. Why having so many women doctors is hurting the NHS: a provocative but powerful argument from a leading surgeon Daily Mail [Internet]. 2014 [cited 2018 May 23].

8. McQuoid-Mason D. Harm to patients and others caused by impaired junior doctors compelled to work 30-hour shifts or longer: can the minister of health, provincial MECs for health and public health officials be held liable? S Afr J Bioeth Law. 2016;9(2):52.

9. Peterson C. Junior doctors working long shifts. The Mercury. 2016 [cited 2016 June 22]. 